\title{
DIFFERENCES OF THE LATVIAN POPULATION PERCEPTIONS AND MEMORIES OF THE DAILY ACTIVITIES OVER 30 YEARS
}

\author{
Zane Ulmane \\ Rīga Stradin̄š University, Latvia \\ Kristīne Šneidere \\ Rīga Stradiņš University, Latvia \\ Gatis Upesleja \\ Rīga Stradiņš University, Latvia \\ Ainārs Stepens \\ Rietumu Clinic, Latvia
}

\begin{abstract}
Regular physical activity helps to improve physical and mental functions as well as reverse some effects of chronic disease to keep older people mobile and independent (McPhee et al., 2016). However, physical activity with aerobic load elements could be a contributing factor to aging (Prakash, Voss, Erickson, \& Kramer, 2015). Epidemiological studies have shown that the intensity of daily physical activity might have an important role to maintain lifelong cognition (Kimura, Yasunaga, \& Wang, 2013). The aim is to identify differences Latvian time use from the retrospective surveying primary data from Total Life-span Physical Activity questionnaire and tertiary data from 1979 published data on population time use and trends (Eglite, Svikis, \& Zarina, 1979). Methods: The primary data of daily activities was from April to December 2019 obtained from the retrospective questionnaire "Total Lifespan Physical Activity questionnaire" (Ulmane, Šneidere, \& Stepens, 2019) and tertiary data were used from 1979 published data on population time use and trends (Eglite, Svikis, \& Zarina, 1979). The data were adjusted to six physical activity categories to be comparable - Work/education, physiological needs, Transportation, Leisure time, Household activities and Sports. Results: did not affect males and females differently in these measures, but only differences of some categories. Results show that the most differences were found in the categories - transportation, household activities, and sport. Conclusions: The study had several limitations because data from the 1979 published book (Eglite, Svikis, \& Zarina, 1979) was only available in aggregate form. Together these results provide important insights into the difference between the capital city, small towns or rural areas, but 2019 study respondents were almost always from the capital city. However, in the future for more precise data analysis needed primary or secondary data.
\end{abstract}

Keywords: life-time, physical activity, primary data, tertiary data. 
Ulmane et al., 2020. Differences of the Latvian Population Perceptions and Memories of the Daily Activities Over 30 Years

\section{Introduction}

In recent years, there has been an increased interest in healthy aging. Aging is one of the growing priorities worldwide (WHO, 2015). Low levels of physical activity (PA) are a global concern and increasing PA engagement is becoming a priority in current public health policies (Puggina et al., 2017). Aging correlates with high risk for physical and cognitive impairment, which contribute to disability to do some simple household activities, physical exercises and possible loss of independence (Bruderer-Hofstetter et al., 2018). Thanks to daily physical activities, people can improve their physical and mental (such as cognitive processes) functions, as well as reduce the risk of developing cardiovascular diseases, to allow older people to be more independent and mobile (McPhee et al., 2016).

As other authors have already mentioned, the importance of physical activity in maintaining the health of the elderly (Stessman, 2009), however, there is a lack of information on behavioral changes in physical activity throughout life, particularly the transition from mid-life to older age. Authors like Hamer and his colleagues listed important factors that change lifelong physical activity behaviors (Hamer, Kivimaki, \& Steptoe, 2012), such as the transition from elementary to high school (Garcia et al., 1998), transition from high school to university (Burke, Beilin, Dunbar, \& Kevan, 2004), marriage (Raymore, Barber, \& Eccles, 2001), becoming a parent (McIntyre \& Rhodes, 2009) and retirement (Allender, Foster, \& Boxer, 2008).

Muchiri and his colleagues pointed out studies which suggest that physically active older adults benefit from maintained physical health by having fewer cardiovascular diseases, better physical functioning (Manini \& Pahor, 2009), mental health such as lower depression, better cognitive functioning (Kramer, Erickson, \& Colcombe, 2006) (Muchiri, Olutende, Kweyu, \& Vurigwa, 2018). Daily physical activity can decrease the physiological influence of a sedentary lifestyle and raise active life expectancy by reducing the risk of noncommunicable diseases and other conditions (e.g. psychological diseases) (De Lira et al., 2018).

Epidemiological studies have shown that the intensity of daily physical activity might have an important role to maintain life-long cognition. Especially, it applies to elderly people who generally engage in moderate physical activity (i.e., intensive walking) might show a reduced risk of age-related cognitive function (Kimura, Yasunaga, \& Wang, 2013). Active living involves purposeful walking, for example, to the shop or work, use stairs instead of using the elevator, do more household activities, wash dishes, small clothes instead of using washing machines, cook more at home not eating at the restaurant, clean your house with a broom not using some robotic technologies. For elderly people it could be to take care by themselves not others, for example, bathing or have a shower, clean 
their teeth, dressing, clean the house a little, feed a pet, etc. (Muchiri, Olutende, Kweyu, \& Vurigwa, 2018).

Improvements in mental health, emotional, psychological, and social wellbeing and cognitive function are also associated with regular physical activities. Despite these health benefits, physical activity levels amongst older adults remain below the recommended $150 \mathrm{~min}$ /week (Boulton, Horne, \& Todd, 2018). Dumith and his colleagues claim that the prevalence of physical inactivity in the world is 21.4\% higher among women than men (Dumith, Hallal, Reis, \& Kohl, 2011). This means that one in four or one in five does not engage in physical activity, being physically inactive or with lower physical activity levels than recommended from WHO (WHO, 2010). WHO suggested recommendations include aerobic exercises and strength exercises, to reduce the risk of falls, WHO also suggest doing some balance exercises. Elderly people should be as active as they can be, their ability and conditions allow, but only if they are unable to follow the instructions due to health problems (Langhammer, Bergland, \& Rydwik, 2018). However, physical activity with aerobic load elements could be a contributing factor to aging (Prakash, Voss, Erickson, \& Kramer, 2015).

Table 1 The daily activities categories

\begin{tabular}{|l|l|}
\hline \multicolumn{2}{|c|}{ The aim of daily activities } \\
\hline Work/education & $\begin{array}{l}\text { Regular paid full and part-time jobs/ formal education and non-formal } \\
\text { education (Ulmane, Šneidere, \& Stepens, 2019). }\end{array}$ \\
\hline $\begin{array}{l}\text { physiological } \\
\text { needs }\end{array}$ & $\begin{array}{l}\text { Sleep and Self-care (personal hygiene and food consumption) (Ulmane, } \\
\text { Sneidere, \& Stepens, 2019). }\end{array}$ \\
\hline Transportation & $\begin{array}{l}\text { Cycling, walking, using public transportation and driving (Ulmane, } \\
\text { Šneidere, \& Stepens, 2019). }\end{array}$ \\
\hline $\begin{array}{l}\text { Leisure-time } \\
\text { physical activity }\end{array}$ & $\begin{array}{l}\text { Type of physical activity undertaken during an individual's } \\
\text { discretionary time that results in substantial energy expenditure (i.e., a } \\
\text { physically active lifestyle). Physical activity may be undertaken for a } \\
\text { variety of reasons, but one of the main objectives involves improving } \\
\text { morbidity or health outcomes (Motl et al., 2017). }\end{array}$ \\
\hline $\begin{array}{l}\text { Household } \\
\text { physical activity }\end{array}$ & $\begin{array}{l}\text { Includes all domains referring to activities within the home and/or } \\
\text { garden (Williams et al., 2012). }\end{array}$ \\
\hline $\begin{array}{l}\text { Exercise physical } \\
\text { activity (sports) }\end{array}$ & $\begin{array}{l}\text { Domains referring to exercise or other activities that are more vigorous } \\
\text { than usual everyday activities (Williams et al., 2012). }\end{array}$ \\
\hline
\end{tabular}

The object of the research is Total Life-span Physical Activity questionnaire and tertiary data from 1979 published data on population time use and trends (Eglite, Svikis, \& Zarina, 1979), and the aim is to identify differences of the Latvian population perception and memories of daily activities over the 30 years. 
Ulmane et al., 2020. Differences of the Latvian Population Perceptions and Memories of the Daily Activities Over 30 Years

\section{Materials and Methods}

\section{Participants}

This is a comparison study. The primary data of daily activities was from April to December 2019 obtained from the retrospective questionnaire "Total Lifespan Physical Activity questionnaire” (Ulmane, Šneidere, \& Stepens, 2019). Participants were 22 seniors aged from 66 - 80 years $(M=69.3$; $S D=6.68)$ seniors (41\% male). All seniors reported no health problems and were speaking Latvian as a first language.

The tertiary data of daily activities was from 1979 published data on population time use and trends (Eglite, Svikis, \& Zarina, 1979). The survey did not include people who were ill, whose use of time is with a difference, and those who were on vacation, there was no possibility to interview. The data thus obtained represents the distribution of time during a normal working week. Each of the respondents recorded their activities and their duration within one week, as well as their gender, age, education, occupation, family composition and level of well-being. To characterize the average time spent by the population of the republic on an annual basis, the survey was conducted in two periods of the year and in each of these three types of territory - residence in Riga, other cities and rural areas. In total it collected more than 4,000 valid weeks' budgets (Eglite, Svikis, \& Zarina, 1979).

\section{Measures and Procedure}

The first for equal compare the data for the daily activities in this study data was selected from the retrospective questionnaire "Total Lifespan Physical Activity questionnaire" (Ulmane, Šneidere, \& Stepens, 2019) those respondents who were at least 15 years old before the 1979 year. The Total Lifespan Physical Activity questionnaire (Ulmane, Šneidere, \& Stepens, 2019) was conducted at Riga Stradiņ̌ University. The questionnaire does not only include information regarding sports activities during the lifetime, but also normal daily activities, such as housework, transportation, and leisure time activities, and questionnaire consists of eight parts (work, education, sleep, transportation, self-care, leisure time, household activities and sports). Work section includes regular paid full and part-time jobs, and divided sedentary work, moderate physical activity work, and vigorous physical activity work. The education section included subsections formal education (high-school, college, university) and non-formal education (seminars, courses, and others). Sleep and naps define the hours spent asleep, and are collected during the interview. Transportation included questions regarding the use of daily transportation and indicated four main types: cycling, walking, using public transportation and driving. Self-care includes personal hygiene compliance (e.g. showering, brushing teeth) and food consumption (e.g. mean meal times). Leisure time was divided into three categories: sedentary leisure 
activities (e.g. reading, watching TV, writing, knitting), outdoor activities (e.g. hiking, visiting a Zoo) as well as social activities (e.g. clubbing, meeting with friends) (Ulmane, Šneidere, \& Stepens, 2019). Leisure-time physical activity may be undertaken for a variety of reasons, but one of the main objectives involves improving morbidity or health outcomes (Motl et al., 2017). Household activity divided Light household activities (e.g. dusting, washing dishes), Moderate household activities (e.g. ironing, laundry washing) and Vigorous household activities (e.g. gardening, repairs) (Ulmane, Šneidere, \& Stepens, 2019). Sports (Exercise physical activity) included purposeful physical activity running, swimming or Nordic Walking), strength (e.g. weight lifting) and group activities (e.g. basketball, volleyball) (Ulmane, Šneidere, \& Stepens, 2019).To investigate life-long physical activity retrospectively was using cognitive interview methods. Cognitive interviewing techniques are often used in retrospective studies. In this study was used verbal probing - asking specific questions with added memory probes (Willis \& Artino, 2013).

But for tertiary data were used from 1979 published data on population time use and trends. At the Institute of Economics of the Latvian Academy of Sciences, the total time use balance of the population of the Republic was elaborated. It describes the distribution of the time fund by type of activity and population. The time budgets needed for the calculations were obtained between 1971 and in 1973 in a special sample survey. The information from survey consists of four parts Total work time - including work, lunch at work, way back and forth from work; Total household activities - household at home, household at auxiliary farming, parenting and child care, Shopping, institutions visiting; Physiological needs; Leisure time together - Study/self-study, Social activities (volunteering), watching performances, active leisure, other types of leisure activities.

Next in this study, we linked from 1979 published data on population time use and trends (Eglite, Svikis, \& Zarina, 1979) capital city with small town and country, because in the retrospective study wasn't fixed demographic location residence for its lifetime. In the second stage in this study were created common categories for comparing data. The data were adjusted to six physical activity categories to be comparable - Work/education, physiological needs, Transportation, Leisure time, Household activities and Sports.

Data analysis

For data analysis was used JASP 0.11.1. To determine the descriptive statistics were calculated to determine averages.

\section{Results and Discussion}

The aim of the present study was to identify differences in Latvian time use over the last 30 years comparing tertiary data from 1979 published data on 
Ulmane et al., 2020. Differences of the Latvian Population Perceptions and Memories of the Daily Activities Over 30 Years

population time use and trends (Eglite, Svikis, \& Zarina, 1979) with primary data from the retrospective questionnaire "Total Lifespan Physical Activity questionnaire” (Ulmane, Šneidere, \& Stepens, 2019). Taken together, these results suggest that there is an association between Latvian population perceptions and memories of the daily activities over the 30 years.

In 1967, a workplace transition began for five working days a week from six working days a week. The new law provided for a 41-hour working week, a maximum of eight hours per day, so it was often necessary to go to work on Saturdays. But the six-hour working day was for teachers and students. In the 1970s, women in Latvia had become equal to men in the labour environment, but women continued to spend significantly more time on household activities than men (Pavlovičs, 2012).

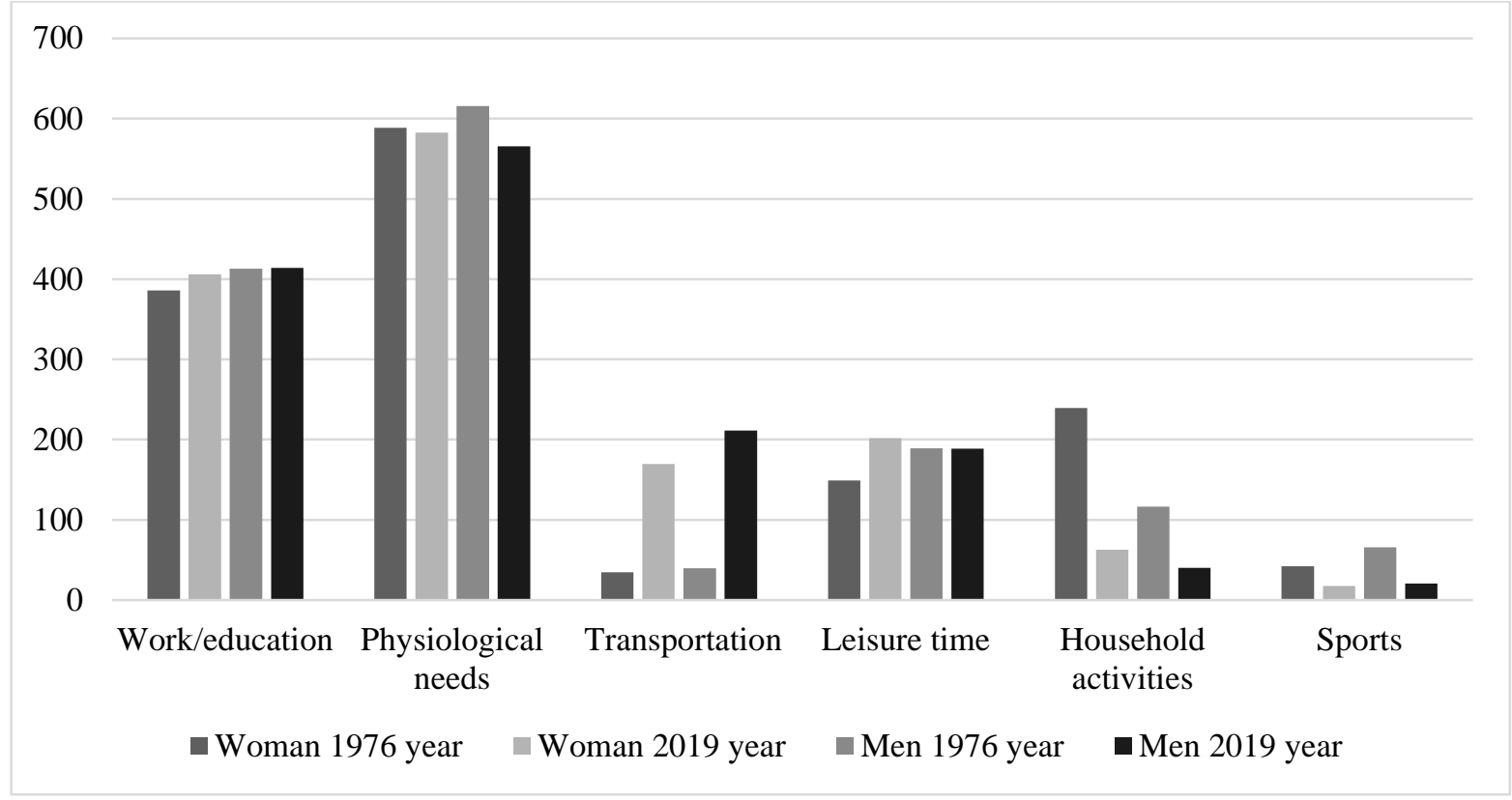

Figure 1 Differences of the Latvian population perceptions and memories of the daily activities over the 30 years (minutes per day)

The chart above shows the proportion of different categories of daily activities from 1979 published data on population time use and trends (Eglite, Svikis, \& Zarina, 1979) and to 2019 obtained data from the retrospective questionnaire "Total Lifespan Physical Activity questionnaire" (Ulmane, Šneidere, \& Stepens, 2019). The average scores of 1979 published data and 2019 obtained data were compared to differences of the Latvian population perceptions and memories of the daily activities over the 30 years for women's and men's groups.

From this data (Figure 1), we can see that 1979 published data resulted in slightly fewer minutes of work/education than 2019 obtained data. Comparing the 
two results, it can be seen that physiological needs are similar before, both also population perceptions and memories of the daily activities. There were significant differences in transportation activities, data from the retrospective questionnaire "Total Lifespan Physical Activity questionnaire" (Ulmane, Šneidere, \& Stepens, 2019) (woman $M=169.7$; men $M=211.4$ ) showed much more minutes than 1979 published data (woman $\mathrm{M}=34.5$; men $\mathrm{M}=39.7$ ). But there were no significant differences between perceptions and memories of the leisure time of the Latvian population. Comparing the results, it can be seen that there were differences between data from the 1979 published data and 2019 obtained data in household activities and sports categories.

Although women had the same working hours as men after working eight hours, women devoted more than one and a half hours to household activities (Pavlovics, 2012), which can also be seen in this study. But there is a difference between woman household activities data from 1979 and primary data from the retrospective questionnaire because the 2019 study (Figure 1) had a smaller sample and the respondents were almost always from the capital city. Capital city people spend significantly less time on household activities, about 1/3 less time, than those who live in small towns or rural areas. The most time-consuming household activities for those who living in Riga is cooking and clothes washing (Drizulis, 1980).

The road to work for the capital city (Riga) was much more time consuming than for small towns or rural people (Drizulis, 1980). It can also be seen in this study (Figure 1) assuming that the data obtained in 2019 is from the capital city population. The same can be observed for leisure time, but this study did not distinguish walking from transportation categories, because data from 1976 reflected only going to and from work, at the same time in 2019 study had to separate all types of transportation. This study combined all of 2019 study data about transportation and categorized under one category because data from 1976 there was only one category that pointed to transportation type. The most common types of leisure time for capital city people were watching television, walking and reading. And leisure time is about $5 \%-25 \%$ less for them who don't live in a capital city. On average over 2 hours a week, every capital city citizen spends time attending theatre shows, concerts or events (Drizulis, 1980). So you can see that in this study there is much more transportation daily activity, but there was no difference in leisure time (Figure 1).

There was a program by the Communist Party of the Soviet Union, which said that people will increasingly devote their free time to social activities, cultural life, mental and physical development. Sports will be firmly anchored in people's daily lives (Eglite, Svikis, \& Zarina, 1979). Maybe that is the reason why there are differences in category "Sports", that men and women spent more time on sports than respondents in this study. 
Ulmane et al., 2020. Differences of the Latvian Population Perceptions and Memories of the Daily Activities Over 30 Years

Pupils and students have significantly more leisure time for different activities (Drizulis, 1980). Therefore comparing tertiary and primary data there may be significant differences. Eglite and colleagues (1979) survey about daily time consumption collected data from respondents from the age of 12 . What is interesting in this data is that other studies and literature on the life of Latvians in the 1970s reflects the changes 2019 obtained data from the retrospective questionnaire "Total Lifespan Physical Activity questionnaire" (Ulmane, Šneidere, \& Stepens, 2019) and data from 1979 published data on population time use and trends (Eglite, Svikis, \& Zarina, 1979). In 1970, only 38\% of the population of Latvia was still lived in the countryside (Pavlovičs, 2012). There are several aspects to the daily consumption of time - place of residence, age, gender, main occupation, family composition, education (Drizulis, 1980).

Overall, these results did not affect males and females differently in these measures, but only differences of some categories. In summary, these results show that the most differences were found in the categories - transportation, household activities, and sport. Together these results provide important insights into the difference between the capital city, small towns or rural areas, but 2019 study respondents were almost always from the capital city. It would, therefore, be necessary to increase the sample of respondents and record where they live at a particular stage of life. The next step in this study is to conduct a deeper analysis of 1979 published data on population time use and trends (Eglite, Svikis, \& Zarina, 1979).

\section{Conclusions}

The study had several limitations because data from 1979 published book (Eglite, Svikis, \& Zarina, 1979) was only available in aggregate form, but in the future for more precise data analysis needed a primary or secondary data. However, generally pointing to a tendency for the difference between the Latvian population perceptions and memories of the daily activities over the 30 years. One of the most pronounced results is about women's leisure time, then and now, if then it was the least time spent on leisure time, but now it 's the most used time also compared to men groups.

Significant differences in results can be observed in the category "Transportation" because women and men in this study approximately spent 5 times more time on transportation than 1979 published data. Overall, these results did not affect males and females differently in these measures, but only differences of some categories. In summary, these results show that the most differences were found in the categories - transportation, household activities, and sport. For further study could be interesting and necessary to increase the sample of respondents and record where they live at a particular stage of life. 


\section{Acknowledgments}

This study was conducted under the RSU project's long-term physical activity on cognitive dysfunction and depression burden on seniors (ELPA-COG) decision of the Scientific Council of 7 March 21/1/1/2019-3.

\section{References}

Allender, S., Foster, C., \& Boxer, A. (2008). Occupational and Nonoccupational Physical Activity and the Social Determinants of Physical Activity: Results From the Health Survey for England. Journal of Physical Activity and Health, 5(1), 104-116.

Boulton, E.R., Horne, M., \& Todd, C. (2018). Multiple influences on participating in physical activity in older age: Developing a social ecological approach. Health Expectations, 21(1), 239-248.

Bruderer-Hofstetter, M., Rausch-Osthoff, A.-K., Meichtry, A., Münzer, T., \& Niedermann, K. (2018). Effective multicomponent interventions in comparison to active control and no interventions on physical capacity, cognitive function and instrumental activities of daily living in elderly people with and without mild impaired cognition - A systematic review and network meta-analysis. Ageing Research Reviews, 45, 1-14.

Burke, V., Beilin, L. J., Dunbar, D., \& Kevan, M. (2004). Changes in health-related behaviours and cardiovascular risk factors in young adults: associations with living with a partner. Preventive medicine, 39(4), 722-730.

De Lira, C.A.B., Taveira, H.V., Rufo-Tavares, W., Amorim, A. dos S., Ferreira, L.M.C., Andrade, M.S., \& Vancini, R.L. (2018). Engagement in a Community Physical Activity Program and Its Effects Upon the Health-Related Quality of Life of Elderly People: A Cross-Sectional Study. Value in Health Regional Issues, 17, 183-188.

Dumith, S.C., Hallal, P.C., Reis, R.S., \& Kohl, H.W. (2011). Worldwide prevalence of physical inactivity and its association with human development index in 76 countries. Preventive Medicine, 53(1-2), 24-28.

Drizulis, A. (1980). Rīga sociālisma laikmetā. Izdevniecība "Zinātne".

Eglite, P., Svikis, A., \& Zarina, I. (1979). Iedzīvotāju laiks. Izdevniecība "Liesma".

Hamer, M., Kivimaki, M., \& Steptoe, A. (2012). Longitudinal patterns in physical activity and sedentary behaviour from mid-life to early old age: a substudy of the Whitehall II cohort. Journal of Epidemiology and Community Health, 66(12), 1110-1115.

Garcia, A., Pender N., Antonakos, C., \& Ronis, D. (1998). Changes in Physical Activity Beliefs and Behaviors of Boys and Girls Across the Transition to Junior High School. Journal of Adolescent Health, 22(5), 394-402.

Kramer, A.F., Erickson, K.I., \& Colcombe, S.J. (2006). Exercise, cognition, and the aging brain. Journal of applied physiology, 101(4), 1237-1242.

Kimura, K., Yasunaga, A., \& Wang, L.-Q. (2013). Correlation between moderate daily physical activity and neurocognitive variability in healthy elderly people. Archives of Gerontology and Geriatrics, 56(1), 109-117.

Langhammer, B., Bergland, A., \& Rydwik, E. (2018). The Importance of Physical Activity Exercise among Older People. BioMed Research International Volume 2018, Article ID 7856823, 3 pages.

Manini, T.M., \& Pahor, M. (2009). Physical activity and maintaining physical function in older adults. British journal of sports medicine, 43(1), 28-31. 
Ulmane et al., 2020. Differences of the Latvian Population Perceptions and Memories of the Daily Activities Over 30 Years

McIntyre, C.A., \& Rhodes, R.E. (2009). Correlates of leisure-time physical activity during transitions to motherhood. Women \& health, 49(1), 66-83.

McPhee, J.S., French, D.P., Jackson, D., Nazroo, J., Pendleton, N., \& Degens, H. (2016). Physical activity in older age: perspectives for healthy ageing and frailty. Biogerontology, 17(3), 567-580.

Muchiri, W.A., Olutende, O.M., Kweyu, I.W., \& Vurigwa, E. (2018). Meaning of Physical Activities for the Elderly: A Review. American Journal of Sports Science and Medicine, 6(3), 79-83.

Pavlovičs, J. (2012). Padomju Latvijas ikdiena. Apgāds "Jumava".

Prakash, R.S., Voss, M.W., Erickson, K.I., \& Kramer, A.F. (2015). Physical Activity and Cognitive Vitality. Annual Review of Psychology, 66(1), 769-797.

Puggina, A., Aleksovska, K., Buck, C., Burns, C., Cardon, G., Carlin, A. (2017). Policy determinants of physical activity across the life course: a "DEDIPAC" umbrella systematic literature review. European Journal of Public Health, 28(1), 105-118.

Raymore, L.A., Barber, B.L., \& Eccles, J.S. (2001). J. Leaving home, attending college, partnership and parenthood: the role of life transition events in leisure pattern stability from adolescence to young adulthood. Journal of Youth and Adolescence, 30(2), 197-223.

Stessman, J. (2009). Physical Activity, Function, and Longevity Among the Very Old. Archives of Internal Medicine, 169(16), 1476.

Ulmane, Z., Šneidere, K., \& Stepens, A. (2019). Development of retrospective life-long physical activity questionnaire: first stage. Society. Integration. Education. DOI: http://dx.doi.org/10.17770/sie2019vol7.3701

Willis, G.B., \& Artino, Jr., A.R. (2013). What do our respondents think we're asking? Using cognitive interviewing to improve medical education surveys. Journal of Graduate Medical Education, 5(3), 353-356.

World Health Organization. (2015). World report on Ageing and Health. Retrieved from www.who.int/ 